\title{
Obstrução estrangulada de jejuno como complicação pós-operatória de ressecção do cólon maior eqüino: relato de caso
}

\author{
[Jejunal strangulative obstruction as a post-operative complication of large colon \\ ressection in a mare: case report] \\ C.A. De Marval ${ }^{1}$, M.R.F. Matos $^{2}$, V.G. Andrade ${ }^{2}$, B.B. Leal ${ }^{1}$, G.E.S. Alves ${ }^{3}$, \\ H.P. Oliveira ${ }^{3}$, R.R. Faleiros ${ }^{3 *}$ \\ ${ }^{1}$ Aluno de pós-graduação - EV-UFMG - Belo Horizonte, MG \\ ${ }^{2}$ Aluno do curso de especialização - DCC-EV-UFMG - Belo Horizonte, MG \\ ${ }^{3}$ Escola de Veterinária - UFMG \\ Caixa Postal 567 \\ 30123-970 - Belo Horizonte, MG
}

\begin{abstract}
RESUMO
Em uma égua, submetida à laparotomia para correção de vólvulo do cólon maior, realizou-se enterectomia próximo ao ligamento cecocólico seguida de enteroanastomose término-terminal. Nas primeiras 24 horas do período pós-operatório, houve piora dos sinais clínicos, com ocorrência de dor, refluxo enterogástrico e agravamento do quadro de endotoxemia. Frente ao prognóstico desfavorável, optou-se pela eutanásia. Durante a necropsia, não foram constatadas falhas na enteroanastomose ou sinais de peritonite séptica. Observou-se encarceramento de uma alça de jejuno, que se apresentava justaposta à extremidade livre da prega cecocólica e comprimida entre o corpo do ceco e o cólon ventral direito remanescente, caracterizando obstrução do tipo estrangulada. Esse achado foi compatível com o agravamento do quadro clínico observado no pós-operatório. Essa ocorrência sugere a necessidade de uma adaptação na técnica de ressecção do cólon maior, de forma a reduzir o espaço cecocólico e evitar um possível encarceramento de alças de intestino delgado.
\end{abstract}

Palavras chave: eqüino, cólica, cólon maior, vólvulo, prega cecocólica

\begin{abstract}
A mare subjected to laparotomy to treat a large colon volvulus had the large colon transected close to the cecocolic ligament followed by anastomosis using end-to-end technique. Despite intensive care, worsening of the clinical signs occurred during the first 24 hours after surgery including pain, enterogastric reflux and grievance of the endotoxemia symptoms. Euthanasia was performed. During necropsy, no signs of failure of the anastomosis and peritonitis were found but a strangulated segment of jejunum was observed adjacent to the cecocolic fold and compressed by the body of the cecum and the reminiscent rigth ventral colon. This finding was associated with the worsening of the clinical signs during the post-operative period. This report indicates that an adaptation in the large colon resection technique reducing the cecocolic space may be beneficial in avoiding such complication.
\end{abstract}

Keywords: mare, colic, large colon, volvulus, cecocolic fold

Recebido em 23 de agosto de 2005

Aceito em 2 de abril de 2007

*Autor para correspondência (corresponding author)

E-mail: faleiros@vet.ufmg.br 


\section{De Marval et al.}

\section{INTRODUÇÃO}

Segundo dados internacionais, as afecções que envolvem o cólon maior (cólon ascendente) representam, em média, 28,6\% dos casos de cólica em eqüinos, sendo a taxa de óbito estimada em 40,5\%. Desses, 19,5\% representam obstruções simples, com $22,2 \%$ de casos fatais. As obstruções estranguladas representam apenas $7,2 \%$ dos casos de cólica, no entanto, a taxa de óbito é alta, representando $71,5 \%$ dos casos (White, 1990). No Brasil, são poucos os dados sobre o estudo. Pesquisas realizadas em hospitais veterinários do estado de São Paulo mostraram que o vólvulo de cólon maior, apesar de mostrar baixa prevalência (Silva et al., 1998), apresenta, à semelhança de outras obstruções estranguladas, taxa de óbito elevada (Lacerda Neto et al., 1994).

Frente ao prognóstico desfavorável, o destino do paciente portador de um quadro grave de torção de cólon, com características de inviabilidade de alça, é quase sempre a eutanásia. Contudo, técnicas de ressecção e anastomose do cólon maior têm sido desenvolvidas (Hughes e Slone, 1998). Estudo realizado por Rose e Bradley (1992) demonstrou que com o uso de uma técnica de ressecção e anastomose, a taxa de sobrevivência foi de $66 \%$, contra $36 \%$ quando se realizaram apenas descompressão e redução do vólvulo de cólon maior.

Contudo, a ressecção do cólon maior é uma técnica sujeita a várias complicações. O cólon maior é um segmento intestinal de grandes dimensões, possui em média 3,4 metros de comprimento e capacidade variando entre 55 e 130 litros (Sisson, 1986), e o acesso cirúrgico não permite a sua completa exposição. Assim, a enterectomia máxima é realizada próxima ao ligamento cecocólico, permanecendo parte dos cólons ventral e dorsal direitos, correspondentes a cerca de 5 a $10 \%$ de sua extensão (Bertone et al., 1990). A exposição dificultada e a extensa área a ser retirada também favorecem a contaminação da cavidade abdominal durante o ato cirúrgico. Além disso, a torção do cólon maior é um quadro extremamente agudo, promovendo isquemia e rápida desvitalização da parede intestinal. Dessa forma, as complicações resultantes da migração transmural de bactérias e seus lipopolissacarídeos se iniciam de forma precoce, muitas vezes antecedendo $\mathrm{o}$ ato cirúrgico (Hughes e Slone, 1997).
Considerando-se a fisiologia digestiva, sabe-se também que o cólon maior é de grande importância para a digestão microbiana dos alimentos e para a absorção de água e eletrólitos (Dart et al., 1999). Portanto, sua ressecção pode levar à diminuição da digestão das fibras e das proteínas e redução da absorção de água resultando em emagrecimento (Bertone et al., 1990).

Este trabalho teve o objetivo de relatar a ocorrência de uma complicação inesperada e não descrita na literatura consultada, caracterizada pelo aprisionamento de um segmento de jejuno no espaço cecocólico durante o período pósoperatório de enterectomia e enteroanastomose para tratamento de uma torção de cólon maior em eqüino.

\section{CASUÍSTICA}

Uma égua, da raça Brasileiro de Hipismo, com 18 anos, foi encaminhada ao hospital veterinário com histórico de sinais de cólica por 24 horas, manifestando dor severa, não responsiva aos analgésicos flunixin meglumine $(1,1 \mathrm{mg} / \mathrm{kg}, \mathrm{IV}) \mathrm{e}$ butorfanol $(0,1 \mathrm{mg} / \mathrm{kg}$, IV). Ao exame clínico, observaram-se mucosas pálidas, tempo de preenchimento capilar (TPC) de 3 seg, freqüência cardíaca (FC) de 80bat/min, freqüência respiratória (FR) de $60 \mathrm{mov} / \mathrm{min}$, temperatura retal (TR) de $38,5^{\circ} \mathrm{C}$, além de hipomotilidade intestinal e fezes amolecidas. Ao exame de palpação transretal, verificou-se posicionamento anormal do ceco, não sendo possível localizar as tênias ventral e medial. Também havia nessa região distensão gasosa e presença de massa compactada. A flexura pélvica e outras áreas do cólon maior não estavam palpáveis.

Pelos exames complementares, verificaram-se hemoconcentração (hematócrito de 55,9\%), proteínas plasmáticas totais no limite mínimo $(5,4 \mathrm{~g} / \mathrm{dl})$ e neutrofilia relativa e absoluta com presença discreta de neutrófilos tóxicos, porém ainda sem leucocitose. O líquido peritoneal continha 2,0g/dl de proteínas totais, 700 células nucleadas totais $/ \mathrm{mm}^{3}$ e 500.000 hemácias $/ \mathrm{mm}^{3}$. A suspeita clínica foi de deslocamento com possível torção do cólon maior, sendo o animal prontamente encaminhado para a cirurgia. 
Após fluidoterapia com Ringer lactato, para restabelecimento da volemia, e pré-medicação com xilazina $(0,5 \mathrm{mg} / \mathrm{kg})$ e éter gliceril guaiacol $(100 \mathrm{mg} / \mathrm{kg})$, o paciente foi submetido à anestesia por isofluorano volatilizado em oxigênio em circuito semi-fechado. Pela celiotomia mediana, confirmou-se a suspeita de deslocamento e torção de cólon maior. Após sua descompressão gasosa, verificou-se que o cólon maior se apresentava em congestão intensa, edemaciado, cianótico, com áreas hemorrágicas na camada serosa e friável. Pela enterotomia do cólon maior para lavagem do conteúdo, previamente à sua exteriorização máxima, observou-se que a mucosa se apresentava enegrecida e hemorrágica.

O cólon foi considerado inviável e optou-se pela enterectomia e enteroanastomose realizada próximo ao ligamento cecocólico. Após a ligadura dupla dos vasos mesentéricos com fio categute cromado número 2 , realizou-se a ressecção dos segmentos de cólons. A enteroanastomose entre os cólons dorsal e ventral direitos foi realizada pela técnica términoterminal (Hughes e Slone, 1997) com dois planos de sutura (simples contínua seguida de Lembert), utilizando-se fio categute número 0 .

Constatada a lesão isquêmica, mesmo antes da ressecção, administrou-se succinato sódico de hidrocortisona $(4 \mathrm{mg} / \mathrm{kg}, \mathrm{IV})$. Após enterectomia, administraram-se, por via intraperitoneal, dimetilsofóxido $(200 \mathrm{mg} / \mathrm{kg})$, heparina sódica $(100 \mathrm{UI} / \mathrm{kg})$ e gentamicina $(4 \mathrm{mg} / \mathrm{kg})$ diluídos em um litro de solução Ringer lactato aquecido a $37^{\circ} \mathrm{C}$. Por via parenteral, foram administrados gentamicina $(4 \mathrm{mg} / \mathrm{kg}, \mathrm{IV})$, penicilina procaína $(30.000 \mathrm{UI} / \mathrm{kg}, \quad \mathrm{IM})$ e flunixin meglumine $(1,1 \mathrm{mg} / \mathrm{kg}, \mathrm{IV})$. A celiorrafia foi realizada com sutura simples contínua com fio de poliamida calibre $0,80 \mathrm{~mm}$. O tecido subcutâneo foi aproximado por sutura contínua com poliglactina 910 número 0 e a pele por pontos simples separados com fio de náilon número 0 . Por entre as suturas foi colocado um dreno, sonda gástrica de Levine, número 18, para posterior lavagem da cavidade abdominal.

A recuperação anestésica ocorreu de forma satisfatória, com o paciente posicionado em estação 33 minutos após o fim da anestesia. Nesse momento, o animal apresentou FC de $82 \mathrm{bpm}, \mathrm{FR}$ de $8 \mathrm{mpm}$, TR de $36,6^{\circ} \mathrm{C}$ e TPC de 3seg. As mucosas estavam pálidas e havia presença de halo cianótico e atonia intestinal. Três horas após a recuperação anestésica, o animal apresentou nove litros de refluxo via sonda nasogástrica, marrom-avermelhado, e atonia intestinal.

Durante o período pós-operatório, além da antibioticoterapia e administração de antiinflamatório, estabeleceu-se fluidoterapia intravenosa com soluções de Ringer lactado, glicose $5 \%$ e solução salina $(\mathrm{NaCl} \quad 0,9 \%)$ aplicados de forma alternada e suplementadas com cloreto de potássio e gluconato de cálcio. Conjuntamente, infusão contínua de cloridrato de lidocaína também foi administrada $(0,05 \mathrm{mg} / \mathrm{kg} / \mathrm{mim})$, após dose inicial de $1,3 \mathrm{mg} / \mathrm{kg}$.

Doze horas após a cirurgia, os sinais clínicos pioraram, sendo a FC de $88 \mathrm{bpm}$, a FR de $40 \mathrm{mpm}$, o TPC de $5 \mathrm{seg}$ e a TR de $38,8^{\circ} \mathrm{C}$. A mucosa oral estava congesta e com halo toxêmico, havia sinais de dor moderada, e foi auscultada motilidade intestinal aumentada no flanco esquerdo.

Dezesseis horas após a cirurgia, o dreno abdominal foi aberto obtendo-se dele três litros de líquido denso, avermelhado, mas sem precipitação evidente de fibrina. Realizou-se, então, infusão de 15 litros de solução de Ringer lactato associados a $40 \mathrm{ml}$ de neomicina e 25.000UI de heparina sódica, dos quais 11 litros foram recuperados após 10 minutos de caminhada. Após a lavagem, houve melhora discreta nos sinais de dor e diminuição do refluxo.

Próximo de completar 24 horas de pós-cirúrgico, o paciente voltou a ter refluxo gastrintestinal e manifestar dor não responsiva ao flunixin meglumine, além de piora significativa dos sinais clínicos e presença de mucosas cianóticas. Estabeleceu-se contato com o veterinário responsável pelo animal para autorização da eutanásia, face ao prognóstico desfavorável.

À necropsia, observou-se distensão do ceco e da porção remanescente do cólon maior, que se encontravam na posição anatômica. No intestino delgado havia um segmento distinto e escuro, que se insinuava entre o ceco e segmento restante do cólon maior. Ao se deslocar o ceco para o lado esquerdo, pôde-se observar sua face 
visceral, onde se evidenciou, junto à extremidade livre do ligamento cecocólico, a alça de jejuno alterada que estava comprimida entre o corpo do ceco e o segmento remanescente do cólon ventral direito (Fig.1A).

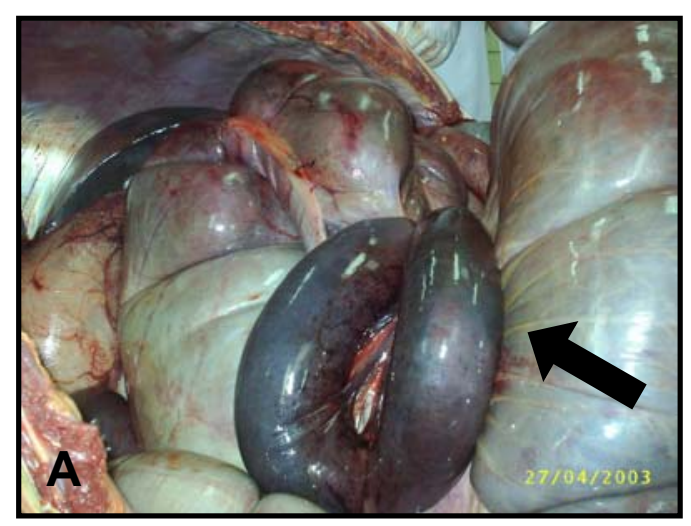

A região da enteroanastomose apresentava-se escurecida na serosa, mas não foram evidenciados sinais de extravasamento, contaminação ou aderências (Fig. 1B). O líquido peritoneal estava vermelho escuro.

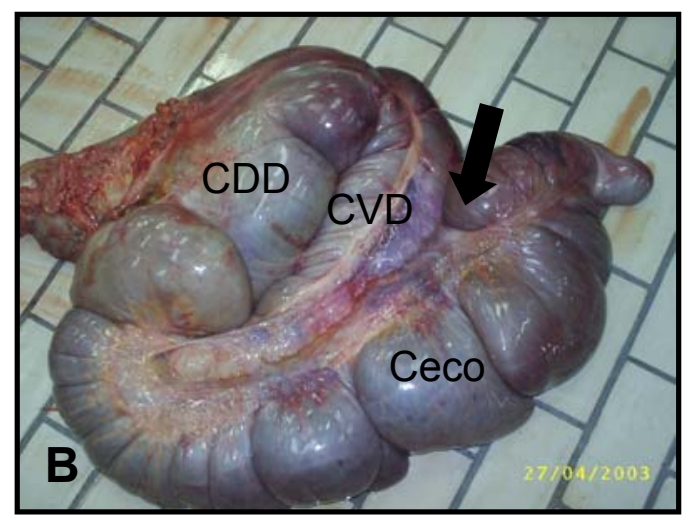

Figura 1. Imagens fotográficas da necropsia de um eqüino submetido a enterectomia e enteroanastomose término-terminal do cólon maior no dia anterior. A - Segmento de jejuno (seta) comprimido entre o segmento remanescente do cólon maior (à esquerda) e o corpo do ceco (à direita). B - Cólon dorsal direito (CDD), cólon ventral direito (CVD) e ceco após a retirada do jejuno. A seta indica o espaço cecocólico.

\section{DISCUSSÃO}

O relato é inusitado pela ocorrência da obstrução estrangulada de uma alça de jejuno entre o segmento remanescente do cólon maior amputado e a face visceral do ceco, junto ao ligamento cecocólico.

O paciente apresentou, inicialmente, um quadro de abdome agudo, com suspeita de obstrução estrangulada. A opção imediata pela cirurgia baseou-se na freqüência cardíaca elevada (80 batimentos/min), na ausência de sons intestinais e, principalmente, no grau de dor apresentado pelo animal e na suspeita de deslocamento percebida durante o exame transretal. Achados semelhantes têm sido considerados como suficientes por outros autores para indicação de cirurgia (Ragle, 1999).

Apesar de o paciente ter apresentado hematócrito elevado, denotando hemoconcentração, as proteínas plasmáticas encontravam-se no limite inferior. Esse achado poderia ter ocorrido devido a perdas para a cavidade peritoneal, fato não confirmado pelo exame do líquido peritoneal. Este achado sugere que as perdas protéicas estavam ocorrendo para o lume intestinal, devido às alterações na mucosa do cólon maior, ou para o espaço extravascular, causadas possivelmente pela endotoxemia já instalada.

A análise do líquido peritoneal mostrou a contagem das células nucleadas totais e a concentração de proteínas totais dentro dos limites normais, não correspondendo à intensidade da lesão encontrada. Esses exames laboratoriais têm sido utilizados para a decisão quanto à indicação de cirurgia e para a determinação do prognóstico, contudo, suas alterações são inespecíficas e seus resultados devem ser considerados em conjunto com as alterações clínicas encontradas (Fischer, 1997). A ausência de alteração significativa desses valores demonstra que ainda não havia dano suficiente na camada seromuscular ou a possibilidade da amostra obtida na colheita préoperatória não ter sido representativa das alterações presentes.

A decisão para se realizar a ressecção do cólon foi baseada no tempo avançado de cólica e nos sinais de inviabilidade intestinal como edema intenso de parede intestinal e mesocólon, coloração escurecida da serosa, ausência de motilidade e, principalmente, na coloração 
enegrecida da mucosa. Embora existam métodos modernos para determinar a viabilidade intestinal, como a análise da perfusão pela fluoresceína, o uso do ultra-som Doppler, a oximetria de superfície e a análise histopatológica transoperatória, nenhum desses tem sido considerado totalmente efetivo (Moore, 1999). Critérios semelhantes aos utilizados neste caso foram adotados por outros autores para determinar a inviabilidade intestinal em cavalos submetidos à ressecção completa do cólon (Rose e Bradley, 1992).

A hemorragia e o edema da mucosa e da serosa foram possivelmente ocasionados pela torção do cólon maior que interrompeu a drenagem venosa, mas não impediu que o sangue arterial continuasse chegando à víscera, provocando aumento na pressão hidrostática da mesma (Dart et al., 1999). Modelos experimentais em cólon maior demonstraram que as obstruções de fluxos venoso e arterial ocorrem com torções acima de $180^{\circ}$ e $270^{\circ}$, respectivamente, e que, em ambos os tipos de obstrução, um período de quatro horas de isquemia foi suficiente para causar necrose completa da mucosa (Allen e Tyler, 1990).

Quanto à realização da técnica de ressecção, a enterotomia do cólon maior para lavagem do conteúdo intestinal, previamente à sua completa exteriorização e ressecção, foi um procedimento que melhorou a exposição da alça intestinal e minimizou a contaminação durante a anastomose. Rose e Bradley (1992) indicaram esse mesmo procedimento. A administração de succinato sódico de hidrocortisona foi indicada por Alves et al. (2003) para reduzir as lesões provocadas pela reperfusão no intestino delgado de eqüinos.

No pós-cirúrgico imediato, a presença de halo toxêmico e o TPC aumentado foram condizentes com um quadro de endotoxemia, comum quando há lesões vasculares graves, como o acontecido neste caso. Hughes e Slone (1997) citaram a endotoxemia e a peritonite como sendo as complicações mais comuns da ressecção de cólon.

A atonia intestinal e o refluxo eram indicativos de íleo adinâmico, que poderia ter sido causado pela anestesia ou por manipulação cirúrgica, endotoxemia e desequilíbrio hidroeletrolítico
(Blikslager et al. 1994). As fezes pastosas com presença de sangue escurecido, observadas durante o exame transretal, também estiveram presentes no relato de nove cavalos submetidos a cirurgia similar (Rose e Bradley, 1992). Possivelmente, a água que permaneceu após a lavagem do cólon, a hemorragia da mucosa e o sangramento intraluminal na região da ressecção causaram esses sinais.

Com a piora dos sinais clínicos no período póscirúrgico, cogitou-se que o estágio de endotoxemia avançado estaria associado a uma possível peritonite ocasionada por desvitalização do cólon maior ou até mesmo uma falha na enteroanastomose, uma vez que a alça estava edemaciada e pouco resistente à aplicação do material de sutura. Frente ao prognóstico desfavorável, optou-se pela eutanásia do animal.

Os achados de necropsia foram inusitados, pois não confirmaram desvitalização do cólon maior. Assim, os sinais clínicos de atonia, refluxo e dor intensa estavam possivelmente mais associados à obstrução estrangulada do jejuno, causada pelo encarceramento de um segmento na região distal da prega cecocólica, entre o ceco e o segmento remanescente do cólon.

Não foram encontrados na literatura consultada relatos de obstrução do jejuno semelhantes ao aqui descrito. $\mathrm{O}$ que mais se aproximou ao ocorrido foi o relato de Gayle et al. (2001) que descreveram a herniação de segmentos do jejuno em áreas de ruptura na região proximal do ligamento cecocólico em pacientes não submetidos previamente à ressecção de cólon. No presente caso, houve obstrução do jejuno e de sua irrigação, não por herniação, mas por sua compressão entre o ceco e o cólon, já que o ligamento cecocólico estava íntegro. Uma possível explicação para o ocorrido seria a ausência do anteparo cranial do cólon maior, normalmente exercido pelas flexuras external e diafragmática. Dessa forma, o segmento de cólon remanescente seria direcionado para uma posição mais vertical, transferindo o apoio para a face visceral do ceco e comprimindo o segmento de jejuno que, ocasionalmente, se localizava na região do ligamento ceco-cólico. Além disso, a diminuição de motilidade do jejuno, causada pelo quadro de íleo adinâmico, pode ter favorecido a permanência dessa víscera naquele espaço. 


\section{CONCLUSÕES}

O fato desse tipo de complicação não ter sido anteriormente relatado indica que se trata de uma eventualidade. Contudo, sua ocorrência sugere a necessidade de uma adaptação na técnica de ressecção completa do cólon maior, de forma a reduzir o espaço ceco-cólico e evitar um possível encarceramento de alças do intestino delgado.

\section{REFERÊNCIAS BIBLIOGRÁFICAS}

ALLEN, D.; TYLER, D.E. Pathophysiology of acute abdominal disease. In: WHITE, N.A. The equine acute abdomen. Malvern: Lea \& Febiger, 1990. p.56-87.

ALVES, G.E.S.; MATTOS, J.J.R.T.; FALEIROS, R.R. et al. Efeito da hidrocortisona sobre a lesão de reperfusão e reparação da mucosa após isquemia venosa experimental no jejuno de eqüinos. Arq. Bras. Med. Vet. Zootec., v.55, p.539-549, 2003.

BERTONE, A.L.; COCKERELL, G.L.; LEE, R.E. et al. Alteration in intestinal morphologic features associated with extensive large-colon resection in horses. Am. J. Vet. Res., v.51, p.1471-1475, 1990.

BLIKSLAGER, A.T.; BOWMAN, K.F.; LEVINE, J.F. Evaluation of factors associated with postoperative ileus in horses: 31 cases (1990-1992). J. Am. Vet. Med. Assoc., v.205, p.1448-1452, 1994.

DART, A.J.; DOWLING, B.A.; HOGSON, D.R. Large intestine. In: AUER, J.A.; STICK, J.A. Equine surgery. 2.ed. Philadelphia: W.B. Saunders, 1999. p.257-285.

FISCHER, A.T. Advances in diagnostic techniques for horses with colic. Vet. Clin. N. Am.: Equine Pract., v.13, p.203-219, 1997.

GAYLE, J.M.; MACHARG, M.A.; SMALLWOOD, E. Strangulating obstruction caused by intestinal herniation through the proximal aspect of the cecocolic fold in 9 horses. Vet. Surg., v.30, p.40-43, 2001.

HUGHES, F.E.; SLONE, D.E. A modified technique for extensive large colon resection and anastomosis in horses. Vet. Surg., v.27, p.127131, 1998.

HUGHES, F.E.; SLONE, D.E. Large colon resection. Vet. Clin. N. Am.: Equine Pract., v.13, p.341-350, 1997.

LACERDA NETO, J.C.; PINTO, L.C.; SCOGNAMILLO,M.V. et al. Estudo retrospectivo dos casos de cólica atendidos no Hospital Veterinário da FCAV - UNESP. Ars Vet., v.10, p.194, 1994. (Resumo).

MOORE, R.M. Principles of intestinal injury and determining intestinal viability. In: AUER, J.A.; STICK, J.A. Equine surgery. 2.ed. Philadelphia: W.B. Saunders, 1999. p.216-223.

RAGLE, C.A. The acute abdomen: diagnosis, preoperative management, and surgical appoaches. In: AUER, J.A.; STICK, J.A. Equine surgery. 2.ed. Philadelphia: W.B. Saunders, 1999. p.224-231.

ROSE, P.L.; BRADLEY, W.M. Resection and anastomosis for treatment of strangulating volvulus of the large colon of horses. J. Am. Vet. Med. Assoc., v.201, p.454-457, 1992.

SILVA, L.C.C.; FERREIRA, M.A.; FANTONI, D.T. et al. Estudo retrospectivo das afecções do intestino grosso em eqüinos, submetidos a laparotomia, no período de janeiro de 1992 a abril de 1998. In: CONGRESSO BRASILEIRO DE CIRURGIA E ANESTESIOLOGIA VETERINÁRIA, 3., 1998, Belo Horizonte. Anais... Belo Horizonte: CBCAV, 1998. p.128. (Resumo).

SISSON, S. Sistema digestivo do eqüino. In: GETTY, R. Anatomia dos animais domésticos. 5.ed. Rio de Janeiro: Guanabara Koogan, 1986. p.424-465.

WHITE, N.A. Epedemiology and etiology of colic. In: The equine acute abdomen. Malvern: Lea \& Febiger, 1990. p.49-64. 